\title{
Informalidad y Derecho
}

\section{Elmer Guillermo Arce Ortiz ${ }^{*}$}

De un fenómeno tan relevante en nuestra sociedad como es la informalidad, poco o nada se ha dicho desde el ámbito jurídico. Es cierto que cada vez son más las investigaciones hechas desde la perspectiva sociológica y económica, sin embargo, se percibe una impresionante omisión por parte de los juristas. $Y$ digo impresionante porque, debido a su incuestionable presencia, la informalidad viene a alterar el tratamiento clásico, entre otros, de dos temas fundamentales del derecho: la organización e interrelación de las normas en el sistema jurídico peruano y la funcionalidad del derecho social.

Conociendo, además, la complejidad del fenómeno de la informalidad no es mi intención abordar cada una de sus proyecciones en la vida real. No entraré, por ello, en un análisis pormenorizado ni del comercio informal, ni del transporte público (Combis), ni de los asentamientos humanos no registrados, ni de las unidades productivas que funcionan al margen de la legalidad como ocurre en el caso de las microempresas. La intención es, repito, extraer los elementos básicos del concepto de informalidad, para luego analizar el impacto de estos sobre instituciones tradicionales del derecho que a la fecha tienen la etiqueta de «incuestionables».

\section{Intentando explicar un fenómeno complejo}

Para empezar, la condición de informal no se puede aplicar a los individuos, sino solo a sus actos o actividades. Ninguna persona puede ser

* Doctor en Derecho por la Universidad de Cádiz. Profesor de Derecho del Trabajo de la Pontificia Universidad Católica del Perú. 
completamente informal, ${ }^{1}$ esto es, actuar en todos los ámbitos de su vida al margen de reglas o normas, pues lo que usualmente sucede es que podrá ser informal en determinados aspectos, pero en otros no (por ejemplo, un ambulante que es informal en la actividad comercial en tanto no paga impuestos al fisco, puede ser formal respecto al pago del impuesto predial por su vivienda). También, en algunos casos la persona que actúa en una determinada actividad dentro de márgenes formales, puede ser formal solo en unos actos e informal en otros (por ejemplo, el empleador que tiene una empresa con registro mercantil y que paga sus tributos legales, puede tener una parte de sus trabajadores contratados verbalmente, sin dar cuenta de ellos al Ministerio de Trabajo). E incluso, en otros casos, la persona puede dar apariencia de formalidad, cuando en verdad vive al margen de la ley (es el supuesto, por ejemplo, de un empresario que consigue una licencia para el funcionamiento de su empresa, pero para una actividad distinta de la que desempeña en la vida real).

En uno de los principales esfuerzos por explicar el tema de la informalidad, Hernando de Soto ha dejado entrever que este fenómeno abarca todos los incumplimientos de las normas y principios que las rigen. Sin embargo, se hace un matiz fundamental, ya que no serán consideradas conductas informales las que infrinjan reglas estructuralmente no tolerables en la sociedad. ${ }^{2}$ Por ejemplo, un narcotraficante o un contrabandista, al incumplir reglas del ordenamiento penal, no solo es un informal, sino además será un delincuente. ${ }^{3}$ De este modo, extrayendo los comportamientos delictivos del ámbito de la informalidad, se puede admitir que es tan informal un ambulante que vende golosinas en una caja de cartón sin constituir una empresa (pues de hacerlo, el pago de impuestos serían superiores a sus ingresos), como el ambulante que tiene cuatro puestos de venta diferentes y que no tributa porque prefiere aumentar sus ganancias.

Ahora bien, este concepto de informalidad deja pendiente un análisis más profundo del fenómeno, pues la informalidad como tal no es un concepto unitario. Al contrario, es "poliforme». Desde nuestro punto de vista, quizá la explicación de la actividad informal, en principio, debe centrarse en dos razones fundamentales: las circunstancias económicas que empujan a las personas a actuar al margen de la ley, de un lado, y la voluntad de no regirse por las normas existentes con el objeto de aumentar las utilidades en una determinada actividad productiva, de otro.

DE SOTO, Hernando. El otro sendero. Lima: ILD, 1987, p. 12.

2 En el mismo sentido, Alberto Bustamante señala que el parámetro para medir la transgresión al tejido institucional es el delito (BUSTAMANTE, Alberto. «Informalidad: superando las viejas tesis». En AAVV. De marginales a informales, Lima: Desco, 1990, p. 18).

3 RUBio CORREA, Marcial. El sistema jurídico. Lima: PUCP, 1991, pp. 251-252. 
Respecto a la primera razón, el hecho de que las personas actúen al margen de las normas existentes es solo un efecto reflejo de lo que ocurre en la realidad económica. La economía peruana, al estar posesionada en la periferia del capitalismo contemporáneo, no tiene ni logra captar suficiente capital como para crear muchos puestos de alta productividad y alta inversión por trabajador. En un mundo globalizado, donde el principio de acumulación de capital ha permitido a las porencias económicas mundiales (Estados Unidos, Unión Europea y Japón) concentrar gran parte de los medios de producción y sus insumos, los países en vías de desarrollo solo pueden mantener inversiones importantes en contados rubros del mercado. Entonces, países como el Perú que cuentan con una pequeña masa de capital y un limitado ritmo de acumulación de este, no hacen otra cosa que excluir del sector formal a una gran masa de mano de obra. ${ }^{4}$ Se crea, pues, un ejército permanente de trabajadores excedentes. ${ }^{5}$

Es decir, el capitalismo globalizado va creando una nueva composición entre los países del mundo que se traduce en una del tipo «núcleo y periferia». Pero eso no es todo, dentro de los países de la periferia se reproduce la misma relación entre los trabajadores insertos en la formalidad y los que no lo están. ${ }^{6}$

Este ejército de trabajadores excedentes, no pertenecientes al núcleo o a la formalidad, para no quedar en el desempleo total, se ve obligado a buscar su propio trabajo para poder sobrevivir. Obviamente, sus utilidades no son tan altas, como ocurre en el sector formal, porque su inversión también es reducida. ${ }^{7}$ Sin embargo, de esta premisa es importante resaltar dos

4 A ello, hay que agregar también otro fenómeno estructural que agrava la situación, como es el veloz crecimiento demográfico de nuestra sociedad. Básicamente, las modificaciones operadas en el campo de la salud a mediados de este siglo han traído desequilibrios en la relación tasa de natalidad y tasa de mortalidad. Antes, tanto la tasa de natalidad como la de mortalidad eran muy elevadas en los países latinoamericanos; sin embargo, esta última se ha reducido abruptamente a partir de la introducción de antibióticos y vacunas.

5 PALMA, Diego. La informalidad, lo popular y el cambio social. Lima: Centro de Estudios y Promoción del Desarrollo, 1987, pp. 25 y ss.

6 Es importante señalar que esta teoría del conflicto social, que aparentemente nos explica el origen del excedente de mano de obra en países periféricos, no es la única que se ha trabajado. Desde un perfil más cercano a la realidad latinoamericana, Daniel Carbonetto ha intentado explicar el fenómeno como un efecto de las «economías coloniales" de la región. El modelo de producción subordinado a los intereses industriales de las grandes potencias, y que se traduce en el suministro de materias primas (guano, salitre, algodón, etc.), no solo retrasó, por ejemplo, el desarrollo industrial peruano, sino que además incentivó la concentración de capital en oligarquías domésticas con limitada proyección mercantil (CARBONETTO, Daniel; Jenny HOYLE y Mario TUEROS. Lima: sector informal, t. I. Lima: CEDEP, 1988, pp. 37 y ss).

7 Palma, op. cit., pp. 37 y ss. 
conclusiones. Primero, el sector informal no es un sector marginal en la economía, pues, al contrario, coexiste con el sector formal. Ambos integran la economía nacional y sus "vasos comunicantes" son múltiples. Por ejemplo, muchos trabajadores del sector formal compran discos compactos en comercios informales al ser más baratos, razón por la cual su nivel de compra también aumenta. De esta forma, la informalidad no tiene presencia en un solo sector marginal de la población sino, por el contrario, se aplica a todos los ciudadanos. Segundo, el sector informal es solo un efecto de la incapacidad del sistema capitalista (actualmente en crisis) para ofrecer empleos decentes que aseguren la supervivencia de todos los ciudadanos. No es, como sugiere De Soto, un simple problema de "costo excesivo de la formalidad", sino un problema estructural del capitalismo que excluye a un segmento de la población. Aún si se bajaran los llamados "costos de la formalidad", es muy difícil exigir la formalización a un colectivo que pugna meramente por sobrevivir.

En cuanto a la segunda razón que contiene esta explicación de la informalidad, hay que resaltar su radical diferencia con las ideas ya planteadas. Si bien la primera causa la hemos relacionado con una característica del capitalismo contemporáneo que empuja a las personas a desarrollar actividades por su propia cuenta para sobrevivir (y no subordinados a otro, como ocurre por regla general en la relación capital/trabajo), la segunda causa de la informalidad se expresa en función de la voluntad del agente de querer autoexcluirse del ámbito de aplicación de la legalidad. En este último caso, la autoexclusión puede producirse en cuanto a toda la formalidad o solo en parte de ella. Puede que alguien quiera desempeñar una actividad productiva y no quiera formalizarse, con el objeto de aumentar su utilidad empresarial al no pagar impuestos ni beneficios laborales a sus trabajadores (por ejemplo, un empresario, dueño de otras entidades empresariales, que desiste en cumplir con todas las formalidades legales de registro de su empresa porque le resta capital de inversión; o el empleador que contrata a sus trabajadores por la vía de contratos civiles, locación de servicios o de obra, cuando lo que corresponde es un contrato laboral). Es más, los motivos para trabajar al margen de la legalidad pueden ser diversos y siempre alejados del fin de la supervivencia; sin embargo, aquí hay una conducta fraudulenta que no debe ser admitida por la ley. Este tipo de informalidad debe ser desmantelada, y como sanción se debe aplicar la ley que corresponde. ${ }^{8}$

s Aquí tenemos una nueva discrepancia con Hernando de Soto, pues el autor de El otro sendero considera que los únicos incumplimientos de la ley que han de estar prohibidos son aquellos que "persiguen fines antisociales, como en el caso del narcotráfico, el robo o el secuestro" (DE SOrO, op. cit., p. 12). Es decir, los incumplimientos de legalidad que la sociedad no tolera por ningún motivo. Sin embargo, ello quiere decir que no importa 
Frente a esta segunda perspectiva, hay que tener en cuenta que muchas veces el infractor realiza un análisis costo/beneficio ante la eventual imposición de sanción. Es decir, si ante una eventual multa su balance de pérdidas y ganancias es positivo o negativo. Si impuesta la multa, su nivel de ganancia es mayor a pagar impuestos y beneficios sociales, entonces preferirá evadir la legalidad. Incluso, en este análisis habrá que atender a otras variables como son la eficacia de la administración estatal para fiscalizar el cumplimiento de las normas o la imposibilidad de pagar sobornos a los funcionarios públicos.

Finalmente, ambos sectores de informalidad no se pueden confundir, a riesgo de desnaturalizar el propio concepto. Son dos ámbitos distintos, frente a los cuales el derecho debe reaccionar de distinta forma. Es cierto que, aunque en teoría, puede resultar fácil distinguir un tipo de informalidad de otra, en la práctica las fronteras suelen ser bastante difusas. ¿Cómo saber si alguien incumple la ley porque necesita hacerlo para sobrevivir o porque tiene una voluntad fraudulenta? Es imposible captar la subjetividad de la persona que incumple la ley. Lo que se puede hacer es operar mediante indicios que permitan deducir la intencionalidad del agente. La administración pública debería llevar un registro de informales con ciertos datos, que permitan conocer su real posición económica. Así, quien no está en la informalidad por supervivencia sino por otro motivo, deberá ser transferido a la formalidad. Y por otro lado, hay que reforzar los sistemas de control de la administración," sobre todo para detectar comportamientos fraudulentos en el sector formal. Hay que evitar que la informalidad sea un pretexto para eludir las normas.

la motivación de quien incumple la norma, pues todo incumplimiento de la ley convertirá al sujeto infractor en un informal. Esto es, claramente, una exageración, por cuanto no es lo mismo la informalidad que tiene por motivo el sobrevivir que la que tiene por motivo el fraude.

9 En esta línea, hay que destacar las novedosas modificaciones a la actual Ley de Inspecciones que ha dispuesto la Ley 28292, publicada el 21 de julio del 2004 en el diario oficial El Peruano. Con la intención de fortalecer la labor de inspección que desarrolla el Ministerio de Trabajo, el nuevo marco formativo, básicamente, de un lado amplía el ámbito de fiscalización de los inspectores $y$, de otro, refuerza la función coercitiva de las multas. En cuanto al primer tema, se admite, a partir de la vigencia de la Ley 28292, que el acto de inspección puede realizarse a iniciativa del propio inspector, sin necesidad de orden de visita otorgada por la Autoridad de Trabajo, siempre que los hechos por inspeccionar pongan en peligro la integridad física, la salud o la seguridad de los trabajadores (artículo 16.4). En cuanto al segundo tema, el empleador que comete una infracción de normas laborales se hará acreedor de una multa desde el momento que se levanta el acta de inspección. Es decir, si antes había que verificar la infracción y, después de treinta días, realizar una visita de reinspección, para recién en ese momento imponer la multa, con el nuevo procedimiento la multa se aplica al tiempo que se verifica por primera vez el incumplimiento (artículo 19.2). 


\section{La informalidad y su efecto en la sociedad peruana}

\subsection{Concepto}

Al ser un fenómeno social y económico, el concepto de informalidad es muy difícil de aprehender. Su heterogeneidad y los límites movibles de sus fronteras complican cualquier ensayo de definición. Sin embargo, a pesar de lo dicho, pensamos que la actividad informal debe concebirse como «un proceso de generación de beneficios, patrimoniales o no, caracterizado por un hecho central: su desviación de la regulación jurídica existente, ya aplicando nuevas regulaciones o ya aplicando regulaciones existentes que no corresponden al cason. Nótese, que el énfasis de la definición se pone en la "desviación de la regulación". No es solo un incumplimiento de la normativa actual sin más, sino que a dicho incumplimiento le sigue otra regulación. ${ }^{10}$

Respecto a la definición mencionada, resta hacer dos consideraciones. Primero, el paso a la informalidad no es equivalente al paso a un «ámbito de la vida" no regulado o exento de toda regulación. Por el contrario, en ciertos casos, el paso a la informalidad constituye un salto a una nueva regulación, pues la normativa existente, o bien no tiene aplicación real a un segmento de la población (recuérdese la exclusión que impone el capitalismo), o bien no se cumple por propia voluntad de quien debiera cumplirla; mientras, en otros, la informalidad no crea una nueva normativa, sino que utiliza fórmulas jurídicas dirigidas a supuestos de hecho distintos.

Segundo, la sucesión de regulaciones o normativas supone que las normas o reglas de contenido jurídico, emitidas por el Estado, van a ser sustituidas por la regulación proveniente de la autonomía privada. Algunas veces, sobre todo cuando existe un grupo organizado de personas que practican la informalidad, la autonomía privada creará reglas insertas en un «sistema de coacción jurídicamente institucionalizado». Para Bobbio, la presencia de un sistema de coacción jurídicamente institucionalizado implica la existencia de una sanción como efecto a la desobediencia de una regla, la medida predeterminada de dicha sanción y las personas encargadas de cumplir

10 Debe anotarse que el concepto de "incumplimiento" será utilizado de una manera amplia. En primer lugar, incumplimiento supone contradicción con una prohibición expresa del ordenamiento. Por ejemplo, el no pago por el empleador de la remuneración mínima vital. En segundo lugar, incumplimiento también supone contradicción con una prohibición implícita del ordenamiento. Por ejemplo, la ley puede decir que los vehículos de transporte público solo circularán con una licencia municipal y ello debe entenderse como una prohibición para los vehículos que no hayan adquirido la mencionada licencia. En este último caso, si bien es cierto que no hay una prohibición expresa dirigida a los vehículos sin licencia, sería ilógico concebir que la prohibición no juega en relación con ellos. 
la ejecución. ${ }^{11}$ Es decir, todo un sistema abocado a la eficacia real de la regulación, esto es, al respeto de un orden. Mientras en otros casos, cuando no hay grupos organizados, la regulación proveniente de la autonomía privada se traducirá en costumbres jurídicas, directivas unilaterales dirigidas a sujetos determinados y acuerdos de voluntad.

Repito, la regulación que varía por las reglas «informales» proviene de poderes normativos estatales (por ejemplo, como ocurre en el caso de la Ley con el Congreso o con el ejecutivo en el caso del Decreto Supremo), mientras que las regulaciones que emergen de la propia sociedad (regulación extra-estatal o social), pueden tener un marco organizado (por ejemplo, estatutos o reglas de las juntas o comités vecinales que se forman luego de las invasiones, con el propósito de negociar con las autoridades el respeto a la nueva propiedad, defender el orden público, tratar de proveer servicios, registrar las propiedades existentes en el asentamiento y administrar justicia por su cuenta) ${ }^{12}$ o un marco no organizado (por ejemplo, entre los ambulantes apostados en las calles tiene que existir alguna costumbre que regule la forma en que se va a dividir la vía pública; o en una microempresa informal, el empresario, aunque remunere por debajo de los mínimos legales, tiene que acordar con su trabajador un monto que retribuya la fuerza de trabajo puesta a su disposición).

Es importante aclarar que el paso a la informalidad puede tener distintos niveles, según la periodicidad con que se produzcan las rotaciones de regulaciones. Así por ejemplo, los primeros informales, llamémosie "pioneros", desvían el cumplimiento de normas oficiales o estatales hacia normas que organizadamente se impongan ellos mismos. Sin embargo, establecidas las normas jurídicas creadas por los pioneros, es posible que posteriormente lleguen otros informales que busquen imponer sus nuevas reglas (sería el caso de una futura organización de las combis "piratas», las cuales circulan sin estar afiliadas a ningún comité). En este último supuesto, la sucesión de regulaciones no sería del tipo estatal/poder social, sino poder social/poder social.

\subsection{Actividades que ingresan en la informalidad}

Dentro del concepto de informalidad, no solo ingresan actividades productivas o comerciales que se podrían derivar de la necesidad de supervivencia, sino también otras que tienen que ver con mejores condiciones de vida. Tal es el caso de las invasiones de asentamientos humanos, por ejemplo. Los

1 Bоввіо, Norberto. Teoría general del Derecho. Bogotá: Temis, 1997, p. 112.

12 Al respecto, es interesante el análisis que De Soto hace respecto de las competencias de las Ilamadas "organizaciones informales" (op. cit., p. 27). 
"excluidos" del sistema formal tienen que asegurar la propiedad de una vivienda dónde subsistir, de alguna manera alternativa a la compraventa. Otro caso sería el de la existencia eventual de "universidades populares", donde nuevamente los «excluidos» del sistema formal tendrían derecho a educación sin la necesidad de un pago de matrícula ni mensualidad.

¿Qué categorías podrían ser calificadas como informales? ¿Qué actividades son informales? Es muy difícil establecer una tipología con parámetros predeterminados, ya que la informalidad es un fenómeno cambiante e infinito. Sin embargo, entre las más conocidas están: las personas que realizan sus actividades en microempresas (pues normalmente se ubican al margen de la legalidad para efectos de sobrevivir), los llamados trabajadores independientes, esto es, las personas que crean su propio empleo (sobre todo, ambulantes), los pobladores de asentamientos humanos sin registro y las personas que lavan carros en la vía pública, entre otros. Aquí, los informales crean una nueva normativa que sucede a la anterior, con el objeto de superar un problema de subsistencia social. Este es el sentido de la informalidad que debe protegerse y apoyarse.

Asimismo, la informalidad no es solo un sector articulado al formal que ha surgido en los países de la periferia capitalista, sino también expresiones de "economía sumergida". En este rubro se pueden citar: contratación de fuerza laboral sin contrato o en condiciones inferiores a lo que disponen normas imperativas, empresas formales que buscan evadir el pago de impuestos, el empresario que tiene una flota de diez Combis y encubre su calidad de empleador alquilándola a otras personas y el despliegue de actividades expresamente prohibidas por el ordenamiento (por ejemplo, prostíbulos clandestinos), entre otros. Esta es una informalidad que, con un control debido, hay que transferir al sector formal.

En cuanto a cifras de informalidad en el Perú, hay que señalar que la mayoría de datos estadísticos no discriminan estos dos ámbitos (informalidad por supervivencia y economía sumergida). Quizá, aparentemente, la única excepción la constituyen los trabajadores independientes, que según la Organización Internacional del Trabajo, en el año 2001 equivalen al 34\% de la población que trabaja en Perú (fuente: revista Panorama Laboral, 2002). Sin embargo, hay que decir "aparentemente", porque dentro de esta categoría se incluye tanto a las personas que crean su empleo por necesidad, como a los sujetos que lo hacen porque prefieren trabajar por su propia cuenta (abogados o profesionales en general que ejercen su labor en oficinas o estudios privados).$^{13} \mathrm{El}$ mismo problema salta a la vista cuando la propia OIT señala que cerca del $19 \%$ de los trabajadores peruanos laboran en

13 Otro factor de distorsión de estos datos estadísticos, es el que tiene que ver con la edad 
pequeñas empresas al margen de la formalidad (fuente: revista Panorama Laboral, 2002). La pregunta es, entonces: ¿cuántos de este 19\% son parte de la llamada "economía sumergida"?

En 1985, por cada cien casas levantadas en Lima, los informales eran propietarios de 69 y los formales solo de 31. Es más, ya en 1984, el transporte público estuvo integrado por $91 \%$ de vehículos informales y solo el $9 \%$ estaba en la formalidad. Es evidente que en estos dos últimos casos, la informalidad es asumida como un bloque que agrupa a quienes necesitan la informalidad para sobrevivir y quienes la toman como pretexto para defraudar el ordenamiento jurídico. Por eso, es necesario inventar mecanismos que permitan diferenciar ambos ámbitos de informalidad.

Finalmente, un ámbito poco explorado de la informalidad, y donde existen pocos datos, es el relativo a infracciones de la legalidad en actividades aparentemente formales. Hay que tener en cuenta que aunque la mayoría de los informales sean ilegales, también los hay legales. Es el caso de quienes solicitan permisos para operar como comercios y después instalan una industria. Incluso, según ciertos estudios, tienen una fuerte presencia en sociedades en vías de desarrollo. ${ }^{14}$

\subsection{Efectos de la informalidad}

Mucho se habla de los informales como un grupo de personas emprendedoras que, con su paso a la formalidad y el acceso a crédito, traerían progreso al país. Es cierto, esta idea, vista a futuro, no debe descartarse directamente. Ya se ha visto que los comportamientos informales han solucionado muchos problemas sociales. Ahí está el problema de la vivienda, pues sin invasiones los distritos de las ciudades peruanas estarían hoy por hoy completamente tugurizadas. Ahí está el problema del transporte público, pues son una respuesta a la incapacidad del sector formal para darse abasto a la demanda de una ciudad tan extensa como Lima.

Sin embargo, pese a lo alentador de esta perspectiva, hay que plantear por lo menos dos reflexiones. Primero, si el sector formal capitalista colapsó, por cuanto es incapaz de generar más trabajo, y no hay una reproducción del capital peruano suficiente para recibir más personas en este sector

de los trabajadores por cuenta propia. Por ejemplo, este $34 \%$ no incluye a los menores de edad que se "ganan la vida" en trabajos independientes. No es que estemos de acuerdo con el trabajo infantil, sino que solo queremos dejar sentado que las mencionadas cifras no demuestran la real dimensión del problema.

14 Sobre el particular, ver el interesante estudio de TOKMAN, Víctor. "La informalidad en los años noventa". En CARPIO, Jorge e Irene NOVACOVSKY (comps.). De igual a igual. Buenos Aires: Fondo de Cultura Económica, 1999, p. 88. 
formal, ¿para qué formalizar? En otras palabras, al recargar impuestos al sector informal, por ejemplo, se estaría quitando ingresos a un colectivo de personas que gana dinero para sobrevivir. Exceptuando a los informales fraudulentos, el sector informal tiene como características: empresas de tamaño pequeño, utilización de tecnologías simples y poco competitivas con las del sector formal, poca inversión capital, y el hecho de que el empresario es, casi siempre, trabajador de esta, entre otros. ${ }^{15}$ De esta manera, si no hay políticas de creación de nuevos mercados la inserción al sector formal de estas actividades resulta ser una mentira. ${ }^{16}$ Ello sería, sin duda, el fin de los actuales informales. Sin embargo, es difícil pensar que el efecto sea el fin de la informalidad, ya que lo normal será que un nuevo grupo de personas venga a desplazar a aquellos e instauren nuevas normas.

Segundo, atendiendo al hecho de que la informalidad es un fenómeno estructural e inherente al capitalismo actual en países como Perú, y que como tal no va a desaparecer, hay que analizar sus efectos sociales con el fin de reducir sus efectos perniciosos. Tanto la informalidad de supervivencia como la economía sumergida excluyen a los sujetos que la conforman del mundo de la formalidad, de la alta producción, de los altos sueldos, es decir, del núcleo productivo. Pero, esta exclusión tiene un efecto todavía mayor respecto al goce de determinados derechos sociales. Por ejemplo, los bajos sueldos constituyen un límite a la integración social, esto es, al goce democrático de la salud, de la educación, etcétera. Es decir, la permanencia de la informalidad, y su análisis como un tema marginal de la sociedad peruana, no hacen otra cosa que segmentar la vida social, profundizar los niveles de precariedad de un sector e incentivar la desintegración social.

\section{La informalidad y el sistema de fuentes del derecho}

Aunque se ha tratado de dar una visión omnicomprensiva de la informalidad, es obvio que cuando nos referimos a sus efectos jurídicos interesa sobre

15 Carbonetto, HoYle y Tueros, op. cit. t. I, pp. 50- 51.

16 Entendiendo esta idea, la Organización Internacional del Trabajo (OIT) ha señalado que: "En muchos países, la enorme escala en que se desarrolla la economía informal ha contribuido a crear conciencia de que hay empresas que no pueden sobrellevar el costo económico de ajustarse a ley, lo cual explica en parte que se compruebe con cierta frecuencia que las empresas de la economía informal están entre las que más infringen las disposiciones de la legislación del trabajo, puesto que el cumplimiento cabal de los requisitos legales está fuera de sus posibilidades. Este hecho sugiere, además, que es preciso apoyar a tales empresas, centros y talleres de trabajo con miras a que progresivamente lleguen a estar en condiciones de cumplir sus obligaciones respecto de los trabajadores". (Véase OrGanización INTERnacional Del Trabajo. El ámbito de la rela. ción de trabajo. Ginebra: Oficina Internacional del trabajo, 2003, p. 10). 
todo la informalidad que es, y debe ser, admitida por el conjunto del sistema jurídico. Esta será solo la informalidad que permita asegurar la supervivencia de un grupo excluido en el marco de una sociedad capitalista poco desarrollada. De este modo, el que se aparta de la legalidad estatal para aumentar sus utilidades será un «informal ilegal o fraudulento". No es posible, por ejemplo, que el ordenamiento no reaccione frente a un sujeto que, autodenominándose "informal", tiene una flota de autos Tico, que alquila a otras personas - quienes, en realidad, debieran estar contratados mediante un contrato laboral (normalmente, estas personas cumplen un horario, una jornada, laboran con un medio de producción "de otro", etcétera) - y que, además, tiene un taller de mecánica para el mantenimiento de los carros y la superación de cualquier siniestro. A este informal, sin duda, hay que reconducirlo a la formalidad.

Como se sabe, el sistema jurídico formalista defendido por Kelsen se ha implantado en gran parte de los Estados positivistas contemporáneos, como el peruano. ${ }^{17}$ Ahora bien, este sistema fundamenta su actuación, básicamente, en dos grandes características: la jerarquía interna de las reglas del propio sistema y su unidad. Una y otra característica van de la mano. Es decir, para establecer una jerarquía en cualquier sistema hace falta que todo se concentre en una unidad. ${ }^{18} \mathrm{Si}$ existieran varios sistemas, aparte del sistema

17 Para el sistema formalista o positivista la validez de una norma jurídica depende únicamente de que el órgano que la emite sea el legitimado y haya respetado el procedimiento previsto en una norma fundamental previa (la Constitución, que es donde reside en última instancia el poder soberano del pueblo). Esta teoría de validez del derecho repara solo en el aspecto formal de las normas, sin importar su contenido ético-político y menos una idea teleológica de este. Por el contrario, aunque destronado por el sistema formalista, hay que aclarar que el sistema iusnaturalista defiende la validez de una norma siempre que esta cumpla con el ideal de justicia, es decir, con un imperativo ético. Sobre los fundamentos del derecho, véase el interesante y didáctico texto de REALE, Miguel. Fundamentos del derecho. Buenos Aires: Depalma, 1976.

18 Esta unidad se va a construir a partir del monopolio de la fuerza normativa que ha de ejercer el Estado. Sin embargo, dado que el Estado cuenta con diversos órganos que emiten diferentes normas jurídicas, sería caótico que estas no cuenten con un orden de aplicación. No se puede imaginar un sistema en el que no exista una subordinación jerárquica de unas normas respecto de otras, salvo que se quieran admitir problemas de concurrencia conflictiva (regulan el mismo supuesto de hecho de modo incompatible) sin solución. Precisamente, el ordenamiento jurídico estatal se autoregula mediante el principio de jerarquía, según el cual una norma de rango inferior no puede contradecir a una de rango superior. En estos términos, véase DE OTTO, Ignacio. Derecho Constitucional, sistema de fuentes. Barcelona: Ariel, 1999, pp. 88-89; y RUBIO CORREA, op. cit., pp. 143 y ss.

A pesar de lo dicho, hay que añadir que, para algunos autores, la concurrencia conflictiva de dos normas de rangos diferentes no genera un conflicto propiamente dicho, en la medida que el conflicto solo se puede generar respecto de dos normas válidas. ¿Cómo se va a admitir la validez de una norma que transgrede lo dispuesto en una norma de mayor jerarquía? Automáticamente, la norma infractora del principio deberá declararse 
gobernado desde las normas que emanan del Estado, es imposible pensar que desde uno de ellos se pueda imponer una determinada jerarquía, pues todos tendrían, en teoría, igual valor.

Producto de este sistema unitario y jerárquico donde conviven las normas, el Estado ha dado siempre mayor valor a sus reglas jurídicas y se ha encargado de marginar a un segundo plano a las regulaciones provenientes de la autonomía privada que él mismo autoriza. ${ }^{19}$ De ahí que, sobre estos pilares se haya construido la famosa "pirámide kelseniana". La Constitución ocupa el primer escalón de la jerarquía, convirtiéndose en el fundamento por excelencia de todo el orden jurídico del Estado: según su artículo 51, le siguen en la pirámide las normas de rango de ley (Leyes del Congreso, Decretos Legislativos, Decretos de Urgencia, etcétera) y al final siguen los reglamentos generales (básicamente, Decretos Supremos que reglamentan las normas con rango de Ley). Ahora bien, por debajo de estas reglas estatales se ubican las regulaciones provenientes de la autonomía privada. Así, estas regulaciones, que tienen su origen en la sociedad, por ser incorporadas al sistema unitario estatal tienen que pagar un "alto precio", como es la pérdida de libertad. La autonomía privada no puede regular todos los aspectos de la vida, como sí lo hace, por ejemplo, la Ley del Congreso, sino solo los aspectos que la normativa estatal declara como «dispositivos» o «no imperativos». Es decir, donde la norma estatal proscriba la actuación de la regulación privada, esta última no podrá regular.

Esta concepción jerárquica y unitaria del sistema jurídico estatal, pretende, por un lado, eliminar cualquier arbitrariedad en el uso del poder, y por otro, dotar de mayor fuerza al interés colectivo, que supuestamente protege el Estado, respecto del interés particular o de los ciudadanos. Ahora bien, desde la caída de los monarcas absolutistas y durante mucho tiempo, esta idea de unidad del derecho fue un reflejo básicamente de una pretensión revolucionaria de la burguesía liberal. El ideal de libertad que abandera la Revolución Francesa es prueba de que los revolucionarios soñaban con una sociedad igualitaria y con intereses comunes. Sin embargo, la realidad exigía una lectura distinta, no era unitaria sino plural, y no era pacífica en la existencia de un solo interés social, sino que era conflictiva. ${ }^{20}$

inválida $y$, por ende, se elimina el conflicto. Sobre el particular, véase NiNO, Carlos Santiago. La validez del derecho. Buenos Aires: Astrea, 2000, pp. 30-31.

19 Según el artículo $V$ del Título Preliminar del Código Civil, "es nulo el acto jurídico contrario a las leyes que interesan al orden público [...]». De esta forma, ninguna manifestación de voluntad podrá afectar una prescripción jurídica de carácter imperativo.

20 Sobre la concepción "homogénea" del derecho legislativo en el Estado Liberal se ha hablado mucho, aunque se ha puesto énfasis también en que la "unidad" no era producto de una concepción unitaria del mundo, sino que las fuerzas antagonistas (por ejemplo, 
A pesar del pluralismo de intereses sociales que emerge como dato de la realidad, por mucho tiempo la unidad del sistema jurídico fue incuestionable, quizá porque la imposición de la creencia de unidad estuvo promocionada por una fuerza social, como fue la burguesía proveniente del capitalismo, que quiso negar las diferencias. Por ello, la creencia duró mientras la fuerza social de la burguesía liberal tuvo suficiente peso para imponer sus intereses con exclusión de otros (por ejemplo, el interés social de los obreros a finales del siglo XIX), pero ni bien fue perdiendo prevalencia social por el empuje de otras fuerzas sociales, en el marco de la institucionalización democrática, empieza a cuestionarse la idea unitaria del sistema jurídico estatal. Es más, producto de esta realidad social diversa, la tradicional generalidad de las normas, como efecto lógico de un sistema jurídico unitario, se ve afectada cada vez más en la actualidad con normas especiales ${ }^{21} \mathrm{o}$ incumplimientos por fenómenos impulsados por fuerzas sociales de reacción al poder único.

Desde la perspectiva de los incumplimientos de normas que se producen en el fenómeno de la informalidad, no creo que el cuestionamiento a la unidad del sistema afecte de la misma manera a todas las fuentes del Derecho. La Constitución debería ser un límite infranqueable frente a estos comportamientos, no solo por ser la norma base del sistema jurídico, sobre la que se construye su unidad sino, además, porque representa la voluntad general de la sociedad. La Constitución debe ser una norma con nivel cero de evasión o incumplimiento. Esto es, al ser el extracto de principios y valores de una sociedad, no permite que nadie quede exonerado de su cumplimento. De este modo, los sectores de la sociedad que pugnan por emanciparse del cumplimiento de las leyes (no de la Constitución), construyen sistemas jurídicos paralelos a los impuestos por la legalidad. Solo pueden cuestionar la ley o, mejor dicho, el rango infraconstitucional. Nacen fuerzas sociales que quieren equiparar sus normas al poder de las normas

el proletariado y sus movimientos sindicales) aparecían neutralizadas y no encontraban expresión en la ley. Gustavo Zagrebelski señala que «Respecto a la legislación, en cambio, no surgía un problema análogo de unidad y coherencia. Su sistematicidad podía considerarse un dato, un postulado que venía asegurado por la tendencial unidad y homogeneidad de las orientaciones de fondo de la fuerza política que se expresaba a través de la ley, sobre todo porque la evolución de los sistemas constitucionales había asegurado la hegemonía de los principios políticos y jurídicos de la burguesía liberal" (ZAGREBELSKI, Gustavo. El derecho dúctil. Madrid: Trotta, 1997, p. 31).

21 Es sintomático, en la línea de las normas especiales, la importancia creciente de la regulación convencional al interior de las empresas. El convenio colectivo, entendido como el acuerdo destinado a regular las remuneraciones, las condiciones de trabajo y productividad y demás, celebrado, por una parte, por la representación de trabajadores y, por otra, por la representación de los empresarios, genera normas jurídicas (mediante sus cláusulas normativas), en virtud del artículo 28 de la Constitución que le reconoce "fuerza vinculante». 
estatales, ${ }^{22}$ instaurando una especie de "pluralismo jurídico" que tiende a romper el molde de la unidad del sistema kelseniano. Es allí donde debemos ubicar la acción de las regulaciones provenientes de la llamada uinformalidad». Eso sí, la propia «informalidad" estará subordinada indefectiblemente a la Constitución, pues es ella la que ha asumido la función unificadora de los sistemas jurídicos. ${ }^{23}$

Regresando al tema del incumplimiento de normas estatales de rango legal o infralegal, para sustituirlas por normas o regulaciones provenientes de la informalidad, se debe apuntar que en la sucesión de normas o regulaciones, no hay derogación. Simplemente, las normas estatales serán inaplicadas o desplazadas, ya que no son eliminadas del ordenamiento. Decae la aplicación de la norma estatal, pero no para todo su ámbito de aplicación sino solo para un sector de la población. La ley sigue rigiendo para otros sectores de la sociedad. Ahora bien, desde el punto de vista jurídico, lo que sucede aquí es que se alteran los elementos esenciales del "positivismo clásicon, por cuanto la autonomía privada (poder social) ya no se aplica solo en los aspectos permitidos por las normas imperativas, sino que, incluso, puede ser contraria a una norma estatal y tener efectos. ${ }^{24}$ De otro lado, desde un aspecto formal, la nueva regulación proveniente de la autonomía privada puede ser de dos clases: de un lado, puede ser una norma jurídica y, de otro, puede no serlo.

Suponiendo que la norma que emana de la autonomía privada es una norma jurídica, puede asumir a su vez, como ya se dijo, varias formas.

2 Comportamientos contrarios a las leyes y, por ende, desprovistos de la coacción estatal han existido siempre. Un ejemplo es el que nos muestra el riguroso sociólogo Max Weber cuando señala: «Instituciones como la Zadruga yugoslava (comunión doméstica), que se cita como ejemplo para demostrar que la coacción jurídica no es necesaria, carecían solamente de la protección jurídica estatal, pero en las épocas de su mayor extensión tenían la protección coactiva, en alto grado eficaz, de la autoridad de la aldea. Cuando estas formas de conducta consensual echan raíces, perduran durante siglos, sin que se tome en cuenta la coacción jurídica del Estado. El derecho austriaco reconocido judicialmente no sólo era ignorado por la Zadruga, sino que algunas de sus normas se oponían a ella, no obstante lo cual dominaba ésta de hecho la conducta campesina” (WEBer, Max. Sociología del derecho. Granada: Comares, 2001, p. 29.)

2 Recuérdese que antes, esto es, desde la concepción unitaria y jerárquica del sistema normativo estatal imperante en el capitalismo burgués, era la ley la que, con sus reglas generales y abstractas, se encargaba respetar la unidad. Ahora, el cambio es que ante eventuales incumplimientos de la ley y su evidente reducción de ámbito de aplicación, la norma que asume la función de cohesión es exclusivamente la Constitución Política. Por lo demás, tal premisa es lógica, en tanto ciertos aspectos medulares de un Estado de Derecho, como los derechos fundamentales en ella consagrados, no deben ni pueden quedar al arbitrio de las partes. Respecto a los caracteres generales de un Estado de Derecho, véase Díaz, Elías. Estado de Derecho y sociedad democrática. Madrid: Taurus, 1983, pp. 31 y ss.

24 Lo que aportan los comportamientos informales es que las regulaciones creadas por la autonomía privada se apliquen incluso por encima de la ley. 
Primero, si estamos frente a un grupo de personas organizadas que despliegan una actividad informal, el grupo organizado puede emitir reglas dentro de un sistema de coacción jurídicamente institucionalizado. ${ }^{25}$ Por ejemplo, aquí tenemos el caso de los comités de transportistas públicos informales, donde se decide quiénes pueden integrar el comité y se establecen derechos y obligaciones a los miembros del mismo. Si en el sistema tradicional es impensable este comportamiento, pues hay normas efectivas que lo impiden, la informalidad lo hace posible.

Segundo, en el marco de informales desorganizados, juega un papel importante la costumbre jurídica. Para la formación de la costumbre con relevancia jurídica y respaldo estatal, se requiere un comportamiento general en una colectividad, reiterado en el tiempo y que cree conciencia de obligatoriedad en su ámbito de formación. ${ }^{26}$ Recuérdese que, en el caso de la costumbre, los comportamientos reiterados son espontáneos, y nunca existió la voluntad explícita de querer crear la nueva norma. Por ejemplo, es lo que sucede cuando un comerciante ambulante se establece en un determinado lugar de la vía pública, pues hay un respeto a esa costumbre de los demás ambulantes.

Y tercero, otra expresión normativa de la autonomía privada es la decisión de un privado de querer regular con efectos generales a otros sujetos. Sucede ello, por ejemplo, cuando en una empresa informal el empresario otorga un derecho a todos sus trabajadores. No es que las acuerde con cada uno de ellos, sino que lo hace de manera general a todos sus trabajadores. Hay una voluntad explícita de querer crear la nueva formativa, diferenciándose así de la costumbre jurídica. Lo cierto es que, de las tres formas normativas que puede asumir la autonomía privada, esta última es la que revela mayor peligro en el ámbito de la microempresa, pues tanto la creación de un derecho como su desaparición queda en manos del empleador.

Ahora bien, también se dijo que la regulación de la autonomía privada puede no tener efectos de norma jurídica. Es decir, no tiene la calidad de abstracción y de generalidad, pues no se aplica a sujetos futuros sino solo actuales, ni se aplica a sujetos indeterminados sino, por el contrario, a sujetos

25 Según señala Bobbio, «Para obviar los inconvenientes de la sanción interna, o sea su escasa eficacia, y los de la sanción externa no institucionalizada, principalmente la falta de proporción entre violación y respuesta, el grupo social institucionaliza la sanción, esto es, regula los comportamientos de los asociados, y regula también la reacción a los comportamientos contrarios" (BOBBIO, op. cit., p. 110).

26 Para el análisis de los elementos de una costumbre jurídica, como son el elemento objetivo (la repetición generalizada y continuada de una conducta determinada) y otro subjetivo (la creencia de que surgen de ella reglas obligatorias), véase, NEVES MUHICA, Javier. Introducción al Derecho Laboral. Lima: Pontificia Universidad Católica del Perú, 2003, p. 79. 
determinados. Tal es el caso de una directiva unilateral del empleador informal que tiene como destino a unos sujetos determinados o de un acuerdo de voluntades en el interior de una empresa informal. Entiéndase que, pese a no ser normas jurídicas, regulan determinados aspectos. Ahora, la regulación que no tiene carácter de norma jurídica ha de respetar lo dispuesto en las normas de un sistema de coacción jurídicamente institucionalizado o en una costumbre, por poner un ejemplo. Solo podrán regular en los aspectos dispositivos de las normas jurídicas.

El hilo conductor de estos supuestos se traduce en: «La normativa estatal es desplazada en ese momento por regulaciones que emanan de la autonomía privada». Al parecer, se corresponden mejor estas últimas con la realidad, que las primeras. Este es el pluralismo jurídico: ya no hay un solo sistema jurídico que comanda el Estado, aunque sin duda sigue siendo el más fuerte, pero no es el único. El Derecho ya está reconociendo otros poderes sociales con facultades regulativas, al margen del Estado. La diferencia es que antes dejaba el espacio para lo autónomo, cuando él no normaba un supuesto; ahora, habiéndolo normado, acepta regulaciones incluso contrarias a sus prescripciones con el objeto de superar problemas sociales.

Haciendo un ejercicio trigonométrico de adaptación a estos cambios en el sistema de fuentes del derecho, quizá se puede decir que el ordenamiento de fuentes ya no es de tipo "piramidal y jerárquico", sino que es de tipo "circulan". En lo que toca a este trabajo, coexisten dos poderes, el del sector formal y el del sector informal, que se articulan, como ya se ha dicho, en torno a un mismo punto de confluencia que debe ser la Constitución. La Constitución es el único ente que va a dar unidad al Derecho, y donde podrán confluir los distintos sistemas jurídicos que existan. De ahí que la informalidad no pueda suponer desconocimiento de derechos constitucionales o fundamentales. Los derechos humanos son mínimos indispensables tanto para el sector formal como para el informal. Por eso, por ejemplo, el trabajo infantil no debe admitirse ni siquiera cuando se alegue la necesidad de supervivencia (artículo 4 de la Constitución).

Una fórmula similar es la que tiene el artículo 149 de la Constitución respecto a las costumbres en comunidades nativas y campesinas. Dice el artículo: «Las autoridades de las Comunidades Campesinas y Nativas, con el apoyo de las Rondas Campesinas, pueden ejercer las funciones jurisdiccionales dentro de su ámbito territorial de conformidad con el derecho consuetudinario, siempre que no violen los derechos fundamentales de la persona». Como se puede apreciar, la costumbre puede desplazar incluso una ley prohibitiva; sin embargo, la misma costumbre ha de condicionar su vigencia al respeto de derechos constitucionales. Este es una consagración constitucional del llamado "pluralismo jurídico". 


\section{Funcionalidad del Derecho Social}

Tal como se ha visto, el fenómeno de la informalidad es sumamente complejo. No puede concluirse de este trabajo que la informalidad como problema social deba desaparecer, pues un sector de la informalidad constituye, precisamente, un excedente del sistema capitalista de producción. Son personas que si no inventan su empleo o si no trabajan en el marco de la economía sumergida, estarían desempleados. Quizá lo que sí debe desaparecer es la informalidad que se lleva a cabo con propósitos fraudulentos de los individuos. De otro lado, tampoco puede concluirse que la sociedad peruana debe acostumbrarse a convivir con la informalidad, por cuanto ello supone eliminar cualquier posibilidad de solución de este problema estructural.

Es evidente que la reducción de la informalidad es un objetivo a mediano plazo en el Perú, no obstante ello no puede lograrse solo desde un plano jurídico. Las normas, claro está, no pueden solucionar los problemas económicos y sociales, ya que, como máximo, podrán trazar algunas tendencias de solución de conflictos sociales. El tema de dar más trabajo a los peruanos que se hallan fuera del sistema capitalista formal se podrá solucionar en la medida en que se inyecte más capital a nuestro país. Es decir, todo dependerá del crecimiento interno de nuestro mercado de capitales, a efectos de que las inversiones generen mayores puestos de trabajo. No es un secreto que ello se puede incentivar, o bien desde la inversión extranjera, o bien abriendo mercados en el exterior para el exiguo capital nacional.

Digamos que en uno y en otro caso, el Derecho no debe quedarse al margen. Debe regular, aunque es verdad que lo podría hacer con distinta intensidad. Si, por ejemplo, vemos el problema desde la necesidad de consolidar el capital nacional y de permitir mayor acumulación de capital por empresas peruanas, es evidente que, más que las inversiones extranjeras, importa el ingreso de productos a mercados de la región. Mientras las grandes inversiones extranjeras pueden quebrar o sacar del mercado a pequeñas empresas nacionales, en cuanto las grandes empresas pueden reducir con mayor facilidad sus costos de producción, el ingreso de productos nacionales a países de la región puede consolidar la actividad de las pequeñas empresas. Eso sí, la firma de tratados de libre comercio debe ir unido a una actividad estatal que promueva el nivel de competitividad de las pequeñas empresas nacionales. No solo deben ser competitivas para el medio, sino que deben serlo también en el ámbito de mercados externos.

La idea es que el Estado debe crear espacios comerciales, expandir mercados e ir progresivamente formalizando a los informales. Esta lógica de actuación es distinta a la de pedir la formalización de los informales sin abrir mercados. Por ejemplo, la formalización de las actuales MYPE puede 
ser beneficiosa para los sujetos que, fraudulentamente, decidieron incumplir las normas, por cuanto ahora tendrán, por ejemplo, un régimen laboral más beneficioso. Sin embargo, esta formalización obligatoria es perjudicial para los empresarios que incumplen las normas, porque de ello depende su subsistencia. En este último caso, los «nuevos formales» van a desaparecer muy pronto, ya por los costos adicionales que tendrá que asumir su actividad, ya por la competencia desleal de otros «nuevos informales». Esto, precisamente, puede convertirse en un círculo vicioso de nunca acabar. Por ello, hay que buscar ensanchar sobre todo la cuantía del capital nacional.

Ahora bien, junto a estas políticas macro económicas del Estado, el derecho debe inventar un nuevo concepto de derecho social que dé solución al conflicto social producido en las sociedades contemporáneas. La cuestión social, es cierto, siempre ha sido una preocupación del Derecho; sin embargo, la respuesta habrá de tener distintas modulaciones, tomando en cuenta el momento y el espacio geográfico donde se hace el análisis. No es lo mismo hablar de la cuestión social de comienzos del siglo XX en un país europeo que hablar de la cuestión social actual en un país tercermundista o periférico.

En el periodo de entreguerras, el constitucionalismo dio respuestas a la llamada cuestión social obrera. Era la época del industrialismo y del despegue económico de ciertas industrias, a costa de un trato inhumano a muchos trabajadores. Por ello, tanto la Constitución de Weimar en Alemania como la de Querétaro en México, en la década del 20, se convierten en pioneras del reconocimiento de derechos sociales. Esta situación puede tener una lectura histórica, en la que la incorporación de los derechos sociales a los textos constitucionales tiene una relevancia política. A partir de ese momento, los trabajadores son incorporados al sistema jurídico capitalista. Con ello, con la incorporación de los intereses laborales al nivel constitucional, el sistema capitalista de producción asegura su supervivencia. Es decir, otorga derechos a los trabajadores pero, a la vez, asegura que la clase obrera no subvierta el orden liberal. Es un pacto político-social. Recuérdese que solo en 1917 había explotado la revolución bolchevique en el este europeo, y las posibilidades de que se produzcan otras revoluciones contra el régimen de producción capitalista no eran remotas.

En realidad, esta respuesta a la cuestión social fue una respuesta posiblemente adecuada para su momento histórico. No obstante, el problema es que la cuestión social se ha ido transformando. Los cambios del mundo, incentivados por la globalización económica, las innovaciones tecnológicas, la fuerte concentración de capitales en empresas y, en determinados países, la descentralización productiva, entre otros, han reordenado la cuestión social. Para poner un ejemplo, la cuestión social ya no es básicamente obrera, o básicamente clasista. Se han multiplicado o se han fragmentado los sectores 
que participan en la cuestión social (parados o desempleados, trabajadores autónomos, trabajadores empleados, trabajadores obreros, subempleados, etcétera), lo que hace más difícil definir los linderos de la actuación efectiva de "lo social». Por esta razón, la obligación del Derecho es la de inventar un nuevo concepto de derecho social. ${ }^{27}$

Los conceptos tradicionales cada día se alejan un poco más de la realidad. El derecho del trabajo, pilar fundamental del Derecho Social, cada vez se aplica, por ejemplo, a menos personas. Si sus garantías son aplicables solo a las relaciones jurídicas personales, remuneradas y subordinadas, su ámbito de actuación se restringe a no más de la tercera parte de la población económicamente activa peruana, ${ }^{28}$ mientras que los que laboran y se encuentran fuera de este ámbito de protección pasan del $50 \%$ de la población económicamente activa (trabajadores autónomos y economía sumergida).

El Derecho Social debe apuntar a mejorar las condiciones de vida de todos los ciudadanos y no solo de un grupo. Su compromiso debe ser el de lograr una real homogeneización social. ${ }^{29} \mathrm{Si}$ a comienzos del siglo pasado el

27 Mientras el modelo fordista de producción se regía por la organización estable de unos colectivos de trabajadores, los actuales modelos postfordistas se basan, normalmente, en la coordinación de unos individuos móviles. La rotación actual de los trabajadores, mediante contratos temporales o de métodos de descentralización productiva, obliga a pensar en fórmulas normativas que garanticen la protección del trabajador, al margen de tipos contractuales subordinados. Aunque pensando en la sociedad europea, donde ciertamente el sector informal es bastante reducido, el profesor Supiot exige el replanteamiento del Derecho Laboral en Europa. Según señala, la actual condición de asalariado, que liga la subordinación y la seguridad, debería cederle paso a un nuevo «estado profesional de la personan, basado en una concepción global del trabajo. Es más, propone el autor que el derecho del trabajo debe ensamblar las exigencias de igualdad entre hombres y mujeres, de la formación permanente, de las tareas familiares y de la libertad profesional de los trabajadores. Sin embargo, para ello es necesario entender las diferentes formas de trabajo más a la luz de lo que las une que de lo que las separa. Véase SUPIOT, Alain. "Transformaciones del trabajo y provenir del derecho laboral en Europa". Revista Internacional del Trabajo, vol. 118, n. ${ }^{\circ}$, Ginebra, Oficina internacional del Trabajo, 1999, pp. 39- 41.

28 Actualmente, por ejemplo, en el ordenamiento español, se encuentran algunos casos de trabajos autónomos a los que se les aplica la legislación laboral vigente: el reconocimiento del derecho de afiliación a los trabajadores por cuenta propia que no tenga trabajadores a su servicio o la formativa de seguridad e higiene. En el caso italiano, es conocido el profundo interés legislativo por regular a los "parasubordinados", esto es, "las relaciones de colaboración que se concreten en una prestación de obra continuada y coordinada, prevalentemente personal, y aun sin tener un carácter subordinado". Sobre los límites intrínsecos de la regulación del trabajo «subordinado" para dar respuestas a los conflictos presentados en la sociedad actual, se puede ver el interesante estudio de CRUZ VILLALÓN, Jesús. "El proceso evolutivo de delimitación del trabajo subordinado». En Trabajo subordinado y trabajo autónomo, estudios en homenaje al profesor José Cabrera Bazán. Madrid: Tecnos, 1999, pp. 169 y ss.

* Véase Monereo Pérez, José Luis. Fundamentos doctrinales del derecho social en España. Madrid: Trotta, 1999, p. 206. 
grupo relevante que se debía proteger era el sector obrero, ya que la industrialización acelerada así lo determinaba, en la actualidad la industrialización va replegándose y el trabajo se va reduciendo en función de la aparición de máquinas que sustituyen a los humanos. La agenda del Derecho Social debe ser la lucha por la inclusión social y la desaparición de la precariedad, básicamente mediante programas de protección social o de seguridad social, sin importar categorías jurídicas ancladas en el pasado.$^{30} \mathrm{La}$ funcionalidad del Derecho Social tiene una relevancia sobre todo política, de cambio social.

No sirve de nada tener una excelente legislación laboral, que en la mayoría de los casos garantiza los derechos de los sujetos pertenecientes al núcleo de producción capitalista, pues los trabajadores marginales no gozan de estas protecciones. Hay que buscar incluir dentro del concepto de ciudadanía social al conjunto de desempleados que no podrán conseguir trabajo por incapacidad del sistema y no por falta de voluntad, e incorporar a los trabajadores independientes, así como incluir a los trabajadores pertenecientes a pequeñas empresas, combatiendo la precariedad de estos puestos.

Finalmente, el otro efecto del constitucionalismo social debe entroncarse con la protección de la persona que trabaja. No importa que el sujeto labore en una pequeña empresa informal, siempre el piso mínimo de derechos debe partir de los derechos constitucionales. Incluso, los trabajadores independientes deben cumplir su labor, siempre que se respeten sus derechos constitucionales. Por encima de estos mínimos indispensables, el legislador puede establecer diferencias de trato para los informales que buscan su supervivencia, como lo hace en el caso de las MYPE (micro- y pequeñas empresas) y el régimen laboral común (Ley de Productividad y Competitividad Laboral). ${ }^{31}$ Sin embargo, por ningún motivo se podrá despojar al ciudadano de sus derechos fundamentales. Así, los derechos fundamentales penetran en cualquier estructura organizativa que se construya en la sociedad. En el caso de la empresa, es evidente que se deberán respetar los derechos

ol lbidem, pp. 213-214.

31 Hay que aclarar que no estamos de acuerdo con la aplicación de una ley que restrinja, con efectos generales, la protección de los trabajadores. Por ejemplo en la Ley de MYPE peruana (ley 28015), se reduce el periodo de vacaciones o la indemnización por despido a cualquier empresa que tiene menos de diez trabajadores y que tiene menos de 150 UIT por ingresos; sin embargo, ¿qué sucede si un gran empresario decide fragmentarse en unidades menores hasta el punto de ser beneficiario de este régimen especial? Obviamente, obtendría provecho de la ley, aun cuando su patrimonio empresarial no se ajusta al de una micro empresa. Es necesario, por ende, aplicar los beneficios legales solo a quienes emprenden la labor empresarial en la informalidad por razones de supervivencia. Así, una vez más, resulta trascendental detectar las "boisas" de informalidad fraudulenta. 
constitucionales tanto en su vertiente individual como colectiva (prohibición de discriminación, libertad de expresión, de opinión, de reunión, derecho de intimidad, a la integridad física, libertad sindical, huelga, participación colectiva en la dirección de la empresa y un largo etcétera). 